\title{
Coil Occlusion of Wide-Neck Bifurcation Aneurysms Assisted by a Novel Intra- to Extra-Aneurysmatic Neck-Bridging Device (pCONus): Initial Experience
}

M. Aguilar-Pérez, W. Kurre, S. Fischer, H. Bäzner, and H. Henkes

\begin{abstract}
BACKGROUND AND PURPOSE: The pCONus is a new stentlike self-expanding nitinol implant with 4 distal petals, which is fully retrievable and electrolytically detachable. The distal end is implanted inside the aneurysm at the neck. The shaft is anchored in the parent vessel. In selected wide-neck bifurcation aneurysms, the pCONus was used to assist coiling. The device was evaluated for its safety and efficacy.
\end{abstract}

MATERIAL AND METHODS: Twenty-eight patients with 28 wide-neck aneurysms ( 9 recently ruptured) were treated with pCONusassisted coiling at the discretion of the operator. Other treatment options were considered but were discarded due to anticipated difficulties. Technical issues, immediate posttreatment angiographic findings, clinical outcome, and follow-up imaging were assessed.

RESULTS: There were 11 MCA, 7 anterior communicating artery, 1 posterior cerebral artery, 1 A2, and 8 basilar artery aneurysms. Insertion and deployment of the pCONus and subsequent coiling were possible in all cases. There were no clinically evident complications associated with the use of the device. Initial anatomic outcome showed 8 complete occlusions, 9 neck remnants, and 11 incomplete occlusions. Neurologic status remained unchanged at follow-up. Angiographic controls were obtained in 22 patients (mean, 7.5 months). Of these, 13 had complete occlusion, 9 showed improvement, and 7 were unchanged. Four died from SAH sequelae or other diseases, and 2 have not yet undergone follow-up. No intimal hyperplasia was observed.

CONCLUSIONS: The pCONus facilitates coil occlusion of unruptured and ruptured wide-neck bifurcation aneurysms. The device can be deployed safely. Coil retention is sufficient to protect the efferent vessels. So far, no intimal hyperplasia in the shaft has been observed.

ABBREVIATIONS: PCA = posterior cerebral artery; SCA = superior cerebellar artery; WNBA = wide-neck bifurcation aneurysm

C oil occlusion of intracranial aneurysms, both ruptured and unruptured, is safe and efficacious. ${ }^{1,2}$ A major limitation of this treatment technique is related to the geometry of the target aneurysm. A neck of $\geq 4 \mathrm{~mm}$ and a fundus width/neck ratio of $\leq 1$ $\mathrm{mm}$ are unfavorable for simple coiling. ${ }^{3}$ Extrasaccular flow diversion has solved this issue for sidewall aneurysms. ${ }^{4}$ Intra-aneurysmal flow diverters are promising but not yet fully established devices for selected bifurcation aneurysms. ${ }^{5-7}$ For wide-neck bifurcation aneurysms (WNBAs), the techniques to assist coil occlusion include stent placement ${ }^{8}$ and "balloon-remodeling," 9

Received July 29, 2013; accepted after revision September 23

From the Departments of Neuroradiology (M.A.-P., W.K., S.F., H.H.) and Neurology (H.B.), Klinikum Stuttgart, Stuttgart, Germany.

This article is dedicated to Professor Roland Felix for his 75th birthday.

Please address correspondence to Marta Aguilar-Pérez, MD, Department of Neuroradiology, Klinikum Stuttgart, Kriegsbergstr 60, D-70174 Stuttgart, Germany; e-mail: martaaguilarperez@yahoo.es

- Indicates open access to non-subscribers at www.ajnr.org.

三 Indicates article with supplemental on-line table.

http://dx.doi.org/10.3174/ajnr.A3807 both requiring catheter access to at least 1 efferent vessel of the bifurcation. This catheterization can be difficult. Coil-assist techniques without efferent vessel access include the TriSpan device (Boston Scientific, Natick, Massachusetts), ${ }^{10}$ which is no longer available, and the deployment of self-expanding stents with their distal end inside the aneurysm ("waffle cone" technique). ${ }^{11}$ The stents used as waffle cones are not optimized for this purpose and are far from ideal. The pCONus (phenox, Bochum, Germany) is a dedicated neurovascular device that was designed to address the functional needs of an extra-intrasaccular neck-bridging aneurysm implant to assist the coil occlusion of WNBAs. This report summarizes our initial experience with the clinical use of this device.

\section{MATERIALS AND METHODS}

All patients were treated in a single institution by a team of 4 interventional neuroradiologists. The endovascular treatment was either proposed to the patient after interdisciplinary discussion or offered on the basis of the preference of the patient. The decision to assist the coil occlusion by a pCONus was made at the discretion of the senior author. In elective procedures, all patients 


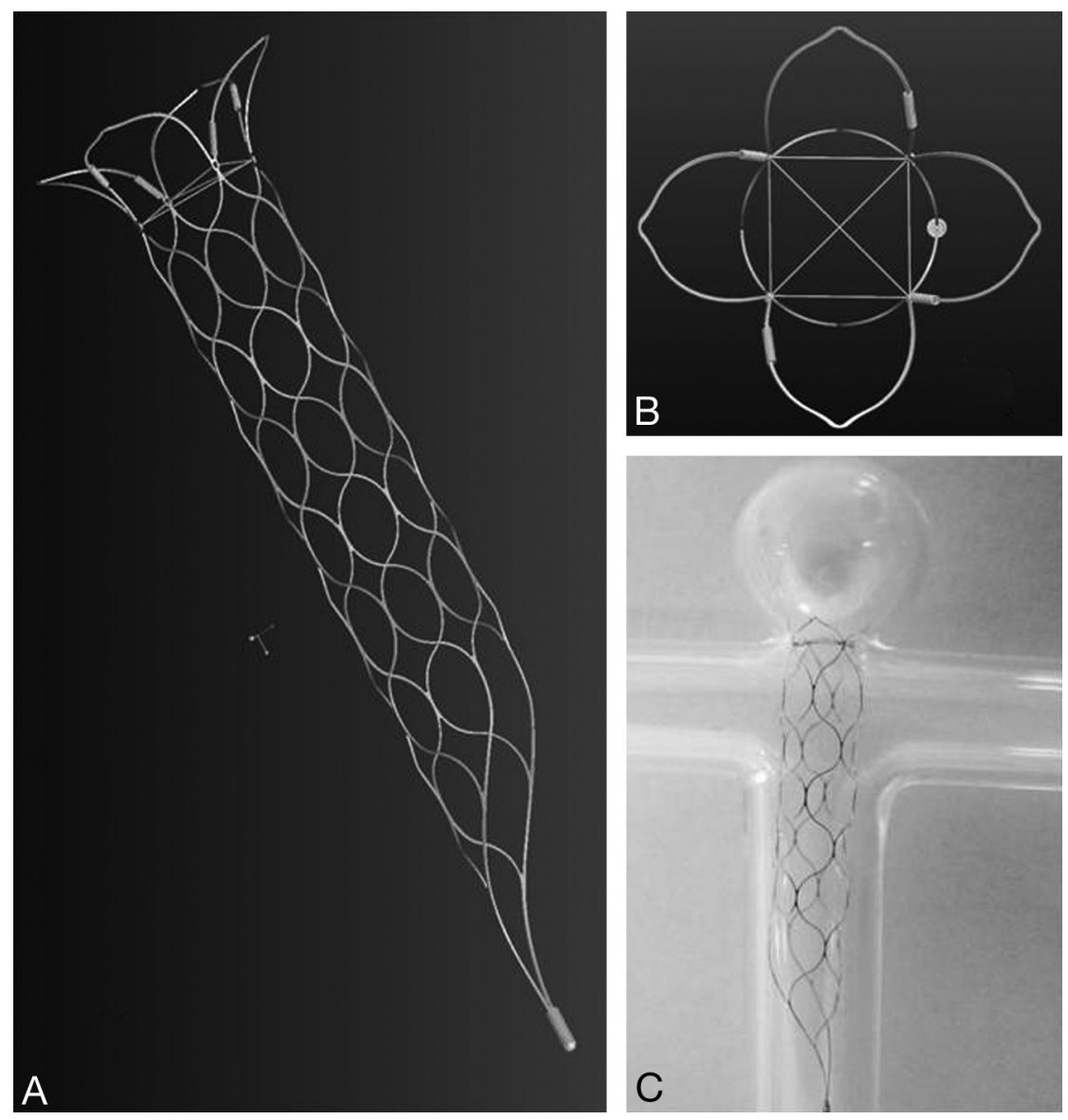

FIG 1. The pCONus is a self-expanding, completely retrievable, electrolytically detachable device with a proximal shaft (similar to stents) and 4 distal petals and a nylon cross in the distal end of the shaft $(A)$. Similar to the waffle cone technique, the 4 distal loops of the pCONus are deployed inside the aneurysm at the level of the neck, assisting coil occlusion (B). The nylon cross (C) prevents coil protrusion into the shaft of the device.

had comprehensive consultations before the procedures. Microsurgery and conservative management were discussed with all elective patients. In patients in the acute phase after SAH, endovascular treatment, including the use of a pCONus, was performed as an emergency measure and, whenever possible, was explained to the relatives. Written informed consent was obtained from all elective patients, from 1 patient before the hemorrhage and from 1 authorized relative of a patient who presented with an SAH.

The pCONus is an endovascular implant for the bridging of intracranial WNBAs to enable coiling (Fig 1). The pCONus is a stentlike laser-cut vessel implant made of nitinol with 4 loops (petals) at its distal end, which are flared in a radial direction. The distal inner diameter of the pCONus is additionally crossed by 6 polyamide fibers, creating a mechanical barrier between the aneurysm and the parent vessel. The biocompatibility of these fibers is certified, and the same material is used for coils with attached nylon fibers (NXT Detachable Coil; ev3, Irvine, California). The proximal end of the implant and the 4 distal loops carry segmental radiopaque markers made of platinum-iridium wire. They allow visual control of the device under fluoroscopy. The pCONus ends proximally in 1 eccentric strut, which carries a detachment element connected to an insertion wire made of stainless steel. This detachment element consists of a cobalt chromium wire, which can be dissolved electrolytically by direct electric current by using available coil-detachment devices. The distal diameters of the expanded petals are available in $5,6,8$, 10,12 , and $15 \mathrm{~mm}$. The stentlike shaft has a $4-\mathrm{mm}$ diameter and is 20 or $25 \mathrm{~mm}$ long. The pCONus is compatible with standard microcatheters with an inner diameter of 0.021 or 0.027 inches (eg, RapidTransit; Codman Neurovascular, Raynham, Massachusetts; and Marksman; Covidien, Dublin, Ireland). We used 0.021-inch microcatheters for easier access. The device allows controlled insertion, deployment, and eventual withdrawal into the microcatheter.

All patients were treated under general anesthesia by using a biplane DSA unit (Axiom Artis; Siemens, Erlangen, Germany). From a femoral access, a $6 \mathrm{~F}$ or $8 \mathrm{~F}$ guide catheter was inserted into the respective cervical vessel. The decision to use a pCONus in all patients was based on anatomic features of the target aneurysm. Single-vessel stent placement was weighed against pCONus usage. Kissing- or crossing-stent placement was not considered as a preferred alternative to the pCONus.

In unruptured aneurysms, a single dose of 500-mg acetylsalicylic acid and 600 -mg clopidogrel was given the day before, and a Multiplate test (Verum Diagnostica, Munich, Germany) was performed before the procedure to confirm sufficient inhibition of the platelet function. Patients 19 and 21 did not show significant platelet-function inhibition and were reloaded with $30 \mathrm{mg}$ prasugrel. Patient 24 was directly premedicated with $180 \mathrm{mg}$ ticagrelor. In patients with severe SAH, the decision for an endovascular treatment was based on an interdisciplinary discussion. Arguments in favor of an endovascular approach were poor clinical condition after SAH or anticipated surgical difficulty. All patients with SAH were treated within 3 days after the index hemorrhage. After insertion of an external CSF drain, patients received $600 \mathrm{mg}$ clopidogrel via a gastric tube and $500 \mathrm{mg}$ acetylsalicylic acid; $5000 \mathrm{U}$ of heparin was given intravenously as soon as the pCONus was deployed.

Postprocedural medication included a daily lifetime dose of $100 \mathrm{mg}$ acetylsalicylic acid orally and $75 \mathrm{mg}$ clopidogrel for 3 months. Patients 19 and 21 were continued with $10 \mathrm{mg}$ prasugrel, and patient 24 , with $2 \times 90$-mg ticagrelor.

In a suitable working projection, calibrated measurements were made to determine the neck width, the aneurysm width, and the aneurysm height. The pCONus size was selected so that complete coverage of the aneurysm neck by the petals could be expected. A 0.021-inch microcatheter (eg, RapidTransit or Prowler Select Plus, Codman Neurovascular) was chosen. The distal end of the pCONus was deployed in the middle of the aneurysm fun- 
dus, avoiding any impact with the aneurysm wall. As soon as the 4 petals were fully opened, the microcatheter was gently pulled back bringing the petals more proximal to the neck of the aneurysm. Without further movement, the insertion wire of the device was kept in place and the microcatheter was pulled back with complete deployment of the shaft of the pCONus. Thereafter, a second microcatheter was inserted through the shaft into the aneurysm fundus (eg, Echelon10, Covidien; or Excelsior SL10; Stryker, Kalamazoo, Michigan). Coil occlusion started with the attempt to create a frame or basket with the first coil (eg, Morpheus coil, Covidien/ev3; or Framing Coil, MicroVention, Tustin, California). The residual space was filled with long and soft coils (eg, HyperSoft; MicroVention). When the fundus was considered completely occluded, the coil catheter was withdrawn and the pCONus was electrolytically detached.

Patients with SAH were managed according to widely accepted Standards of Practice. Patients with unruptured aneurysms underwent an MR imaging examination within 48 hours after the procedure. Angiographic follow-up was scheduled for 3 and 9 months.

Feasibility of the treatment, rate of intraprocedural and postprocedural complications, morbidity and mortality, and immediate and follow-up angiographic outcome were evaluated and assessed by the operators and the first author. The authors made the analysis in retrospect.

\section{RESULTS}

Twenty-eight consecutive patients ( 13 women; median age, 57.35 years) and 28 aneurysms (9 ruptured) were included. Demographic data, aneurysm sizes, and treatment results are summarized in the On-line Table.

Insertion and controlled deployment of the pCONus were possible in all patients. Neither access failure nor aneurysm or vessel perforation occurred. Catheterization of the aneurysms through the shaft of the pCONus did not cause any difficulty. No coil loop protrusion between the petals was encountered.

In 25/28 aneurysms (89\%), a single pCONus alone retained the coils inside the aneurysm sac and protected the efferent vessels. In $2 / 28$ patients, another device was necessary to prevent the occlusion of the efferent vessels. In $1 / 28$ patients, a second pCONus was necessary to protect the neck region of the aneurysm.

Patient 19 presented with a giant MCA aneurysm, for which a combination of a pCONus and a TriSpan was necessary for coil stabilization and protection of the M2 origins.

Patient 23 presented with a fusiform upper basilar trunk and bifurcation aneurysm with both posterior cerebral arteries (PCAs) and superior cerebellar arteries (SCAs) originating from the lateral aspect of the aneurysm. The pCONus alone appeared insufficient to protect the PCA and SCA origins. Just Y-crossing Solitaire stents (Covidien) in both PCAs were expected to incompletely protect the SCAs, with difficult control of the coil occlusion of the saccular component of the aneurysm. After positioning the pCONus petals within the lumen of the aneurysm, we catheterized both PCAs without difficulty and 2 Solitaire stents were deployed in a Y-technique. The resulting structure was stable and allowed a well-controlled coil occlusion of the aneurysm.

In patient 26, a large unruptured aneurysm of the basilar tip incorporated both PCA origins. The aneurysm was directed back- ward toward the brain stem, with a $90^{\circ}$ angle between the axes of the basilar artery and the aneurysm fundus. Two 5-mm pCONus implants were deployed in a crossing position to protect the neck region of the aneurysm.

The 3-point scale of Raymond et $\mathrm{al}^{12}$ was used to evaluate the initial occlusion rate. In $8 / 28$ aneurysms $(28.6 \%)$, the occlusion rate was graded as class 1 (complete), 9/28 aneurysms (32.1\%) were graded as class 2 (neck remnant), and 11/28 aneurysms (39.3\%), as class 3 (residual fundus perfusion). In patients 3 and 18 , an early second treatment within the first week was necessary to achieve the occlusion of the aneurysm (Fig 2).

In 1 patient, a local thrombus formation was observed intraoperatively, which resolved with a body-weight-adapted bolus dose of eptifibatide. Thromboembolic incidents with new ischemic lesions on MR imaging occurred in $9 / 15$ patients $(60 \%)$ and remained clinically silent in all except 3 cases. Three of 28 patients $(10.7 \%)$ showed transient ischemic symptoms after the treatment, which resolved within 1 week. No clinically evident complications with permanent neurologic deficits or death related to the pCONus deployment or coil occlusion occurred.

Of the 28 patients treated, 4 died ( 2 from SAH sequelae and 2 from other diseases) and 2 have not yet undergone follow-up. Angiographic follow-up was available in $22 / 28$ patients $(78.6 \%)$ between 2 and 19 months (mean, 7.5 months) after the treatment. Complete occlusion was seen in 13/22 aneurysms (59\%); neck remnant, in 6/22 aneurysms (27.3\%); and aneurysm remnant, in 3/22 aneurysms (13.6\%). All aneurysm remnant regrowths occurred in large/giant, partially thrombosed aneurysms after initial partial occlusion. No intimal hyperplasia was observed inside the pCONus shaft. Of these 22 aneurysms, 9 showed improvement of at least 1 point on the Raymond grading scale, while 7 remained unchanged.

In the 3 aneurysms with recoiling, access through the implanted pCONus was again possible and coil retention was as reliable as it was during the initial procedure (Fig 3).

\section{DISCUSSION}

WNBAs have been challenging for the endovascular approach. 3D coils were an early and relatively easy-to-use solution for these aneurysms. ${ }^{13} 3 \mathrm{D}$ coils alone work best in long aneurysms, but frequently do not have enough stability in shallow aneurysms and in those without any neck.

The "dual-catheter" technique is another straightforward and inexpensive strategy. ${ }^{14} \mathrm{~A}$ known risk of this technique is the first coil not entirely protecting the vessel bifurcation and displacement of already detached coils by subsequent coils.

The balloon-remodeling technique was initially advocated for sidewall aneurysms. ${ }^{9}$ The development of more flexible and atraumatic compliant balloon catheters allows the simultaneous use of multiple balloons. ${ }^{15}$ Catheterization of the efferent vessels of a bifurcation, however, can be difficult, and the presence of 2 or 3 catheters in the parent vessel unavoidably causes a temporary interruption of the cerebral blood flow and may cause hemodynamic compromise and/or thromboembolic events. The coverage of the aneurysm neck by the inflated balloon is solid, but overinflation may cause vessel dissection; the risk of aneurysm rupture due to coil-induced pressure on the aneurysm wall might be increased. ${ }^{16}$ Besides, the balloon coverage is temporary. If the coils 

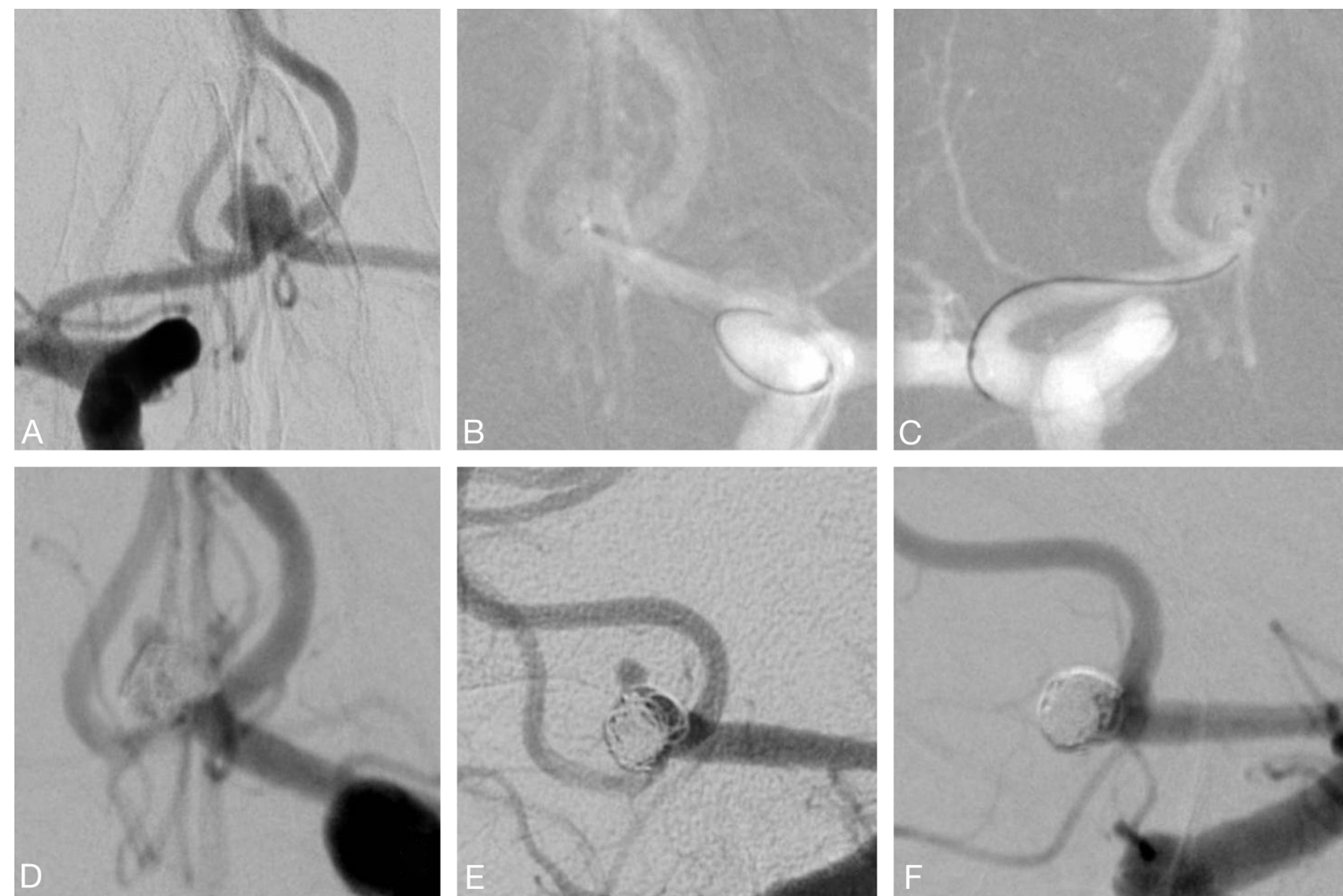

FIG 2. Wide-neck unruptured anterior communicating artery aneurysm in a 68-year-old man; neck diameter, $5.5 \mathrm{~mm}$; fundus diameter, $7 \mathrm{~mm}(A)$. A 6-mm pCONus is inserted via the left $\mathrm{Al}(B)$, with catheter access from the right $\mathrm{Al}$ for coil occlusion (C). A minor neck remnant is accepted; the daughter aneurysm is still filling at the end of the procedure $(D)$ and was expected to thrombose. For safety reasons, early angiographic follow-up was performed 4 days later and showed an incomplete coil occlusion (E). In a second session, complete occlusion of the aneurysm was achieved. The right A2 segment is filling from the ipsilateral ICA. Follow-up DSA 2 months later confirmed complete occlusion of the aneurysm, without compromise on the $\mathrm{A} 1 / \mathrm{A} 2$ segment on both sides $(F)$.

introduced under balloon protection do not stabilize each other, balloon deflation may be followed by coil prolapse into the parent vessel. In the available literature, the safety profile of balloon remodeling was similar to that of unassisted coiling. ${ }^{17}$ If the follow-up occlusion rates post-stent placement are consistently better than those after balloon remodeling, then balloon remodeling remains open to further evaluation. ${ }^{18}$ In our practice, we mainly use balloon remodeling for proximal sidewall aneurysms (eg, in cavernous/paraophthalmic locations).

In comparison with balloon remodeling, the use of the pCONus is easier and more controllable, without interruption of the blood flow and without the need to catheterize the efferent vessels. The need for dual medical antiaggregation for the pCONus is certainly a drawback, especially in ruptured aneurysms.

Neuroform (Stryker Neurovascular), Enterprise (Codman \& Shurtleff), LEO+ (Balt Extrusion, Montmorency, France), Solitaire, and LVIS (MicroVention) are self-expanding stents for the treatment of WNBAs with different features. ${ }^{19}$ Placing a stent over an aneurysm orifice may cause a neck-diameter reduction ${ }^{20}$ and vessel straightening, improving the hemodynamic situation and stabilizing the occlusion rate after coil occlusion. ${ }^{8,21}$ This effect is more important with closed-cell stents than with open-cell ones. $^{22}$ This technique can, however, be technically demanding ${ }^{23}$ and may result in severe complications. In a retrospective analysis of a large series with 216 stented and coiled aneurysms, Piotin et $\mathrm{al}^{21}$ found rates for procedure-related permanent neurologic morbidity and mortality of $7.4 \%$ and $6 \%$, respectively. In their literature survey on stent-assisted aneurysm coiling, Shapiro et $\mathrm{al}^{24}$ evaluated data from 39 articles with 1517 patients. They found a $9 \%$ rate of stent-related technical issues, $4 \%$ failure of stent deployment, a $19 \%$ overall procedure complication rate, and $2.1 \%$ periprocedural mortality.

The bridging of a vessel bifurcation by a single stent may provide insufficient coil retention. A more robust vessel reconstruction can be achieved if stents are deployed in both branching vessels (Y-stent placement). Descriptions of this technique were published for both unruptured and ruptured aneurysms. ${ }^{25,26}$

Cekirge et $\mathrm{al}^{27}$ were the first to emphasize the hemodynamic effect of Y-stent placement. They observed reduced perfusion and final thrombosis of WNBAs after Y-stent placement with Enterprise stents without coiling. One of the reasons that stents such as the Enterprise with relatively large cells become hemodynamically active once they are used in a crossing fashion is the compression and deformation of the stents at their intersection. ${ }^{28}$ For the same reason, catheterization for coiling through crossing an Enterprise can be very difficult if a "jailed catheter" technique was not used. In a recently published multicenter trial, Fargen et $\mathrm{al}^{29}$ reported 45 (mostly basilar apex) aneurysms treated by Y-stent placement 

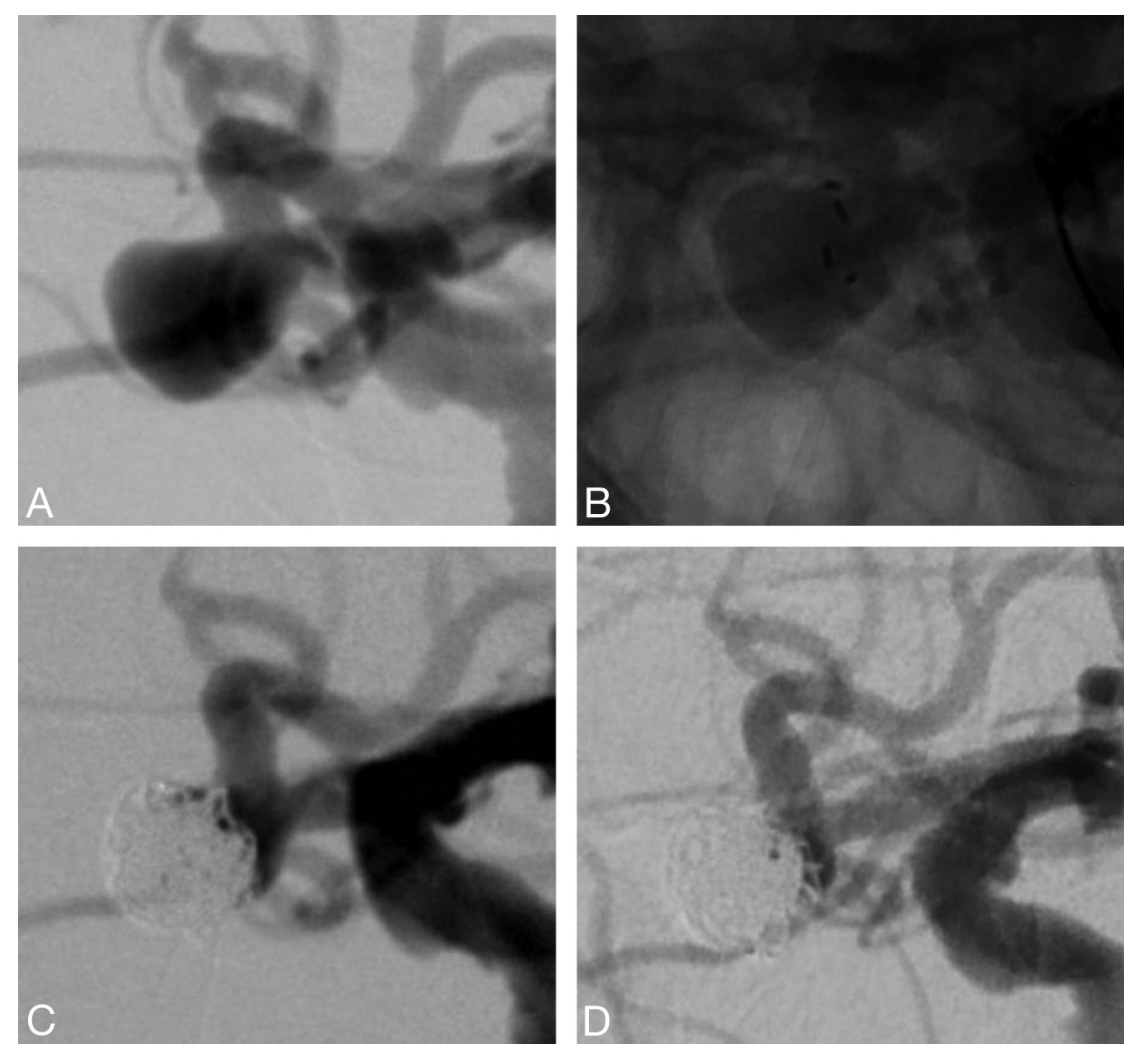

FIG 3. Wide-neck unruptured MCA bifurcation aneurysm in a 65-year-old woman, who rejected the proposed microsurgical clipping of the aneurysm $(A)$. The aneurysm neck and fundus diameters are 5.7 and $8.7 \mathrm{~mm}$, respectively. A 5- $\mathrm{mm}$ pCONus is deployed inside the aneurysm (B), which allows complete coil occlusion (C). Follow-up DSA 9 months later confirms the complete occlusion of the aneurysm $(D)$, without intimal hyperplasia inside the shaft of the pCONus. instead of diverting it away. ${ }^{22,33}$ At this moment, this is a justified concern. Liu et $\mathrm{al}^{34}$ reported good results from 10 aneurysms treated with the waffle cone technique; as in our series, angiographic follow-up showed a stable degree or improvement of occlusion in most aneurysms. An impaired occlusion at follow-up was mainly observed in large and giant partially thrombosed aneurysms. None of the aneurysms treated in the acute phase after SAH re-bled.

The TriSpan neck-bridging device was made of 3 nitinol loops (petals) coated with polyxylylene. Both ends of each petal were fixed to a central platinum coil ("umbilicus, stem”), which was attached to a stainless steel insertion wire. On withdrawal of the microcatheter, the petals of the TriSpan opened similar to a flower blossom. The device was positioned just beyond the level of the neck. Change, correction, or even withdrawal was possible. A second microcatheter was then inserted into the aneurysm between the petals and was used for coiling. Experimental ${ }^{35}$ and early clinical results ${ }^{10}$ were promising, but De Keukeleire et $\mathrm{al}^{36}$ reported, in 14 patients, a complication rate of $37.5 \%$, associated with a low primary complete oc- and coiling, with a rate of $84 \%$ of complete occlusion or neck remnant and an $11 \%$ procedural complication rate.

For Y-stent placement, hemodynamic effects are related to the metal construct in the parent artery and the alteration of the geometry of the efferent vessels. The formation of neointima over crossing stents appears at least unlikely.

The term "waffle cone technique" refers to a situation in which a self-expanding stent is deployed with its distal end inside an aneurysm instead of bridging the neck. Neuroform, Solitaire, ${ }^{30}$ LEO +, and Enterprise ${ }^{31}$ stents have been used for this purpose, but they share features that are far from ideal for this purpose. The Enterprise, for instance, has a smaller cell size and less radial force than the Solitaire and pCONus, ${ }^{19}$ and stent migration has been observed. ${ }^{32}$ The risk of migration is even higher if the distal end of the Enterprise stent is placed inside an aneurysm, with an axial outward force exerted by the coils. The intended use of the pCONus is similar to the waffle cone deployment of the abovementioned stents, with the difference that the pCONus is made and optimized for this purpose. The Enterprise stent has flared distal ends, and the Solitaire AB has 4 sharp ends with radiopaque markers. Both are potentially more traumatic to the aneurysm wall than the pCONus petals. The waffle cone and pCONus techniques are theoretically superior to crossing-stent placement because less material is deployed inside the blood stream, ${ }^{33}$ but it has been suggested that this technique can worsen the hemodynamic situation by directing the blood stream toward the aneurysm clusion rate and a high recurrence. A specific concern of this device was thromboembolic events, presumably related to the large foreign body surface in conjunction with inconsistent medical antiaggregation. The proper deployment of the TriSpan device was critical in aneurysms with a significant asymmetry or in the case of a steep angle between the longitudinal axis of the parent vessel and the aneurysm fundus. The TriSpan, once detached, had no further fixation. It was, therefore, necessary to either stabilize the device at the aneurysm wall or intermingle coils and TriSpan petals to create a self-stabilizing conglomerate. The TriSpan never gained FDA approval, and its production was terminated in 2007.

Similar to the TriSpan, the pCONus can be repositioned and/or withdrawn. The positions of the 4 pCONus petals (instead of 3 TriSpan loops) are, however, more stable due to their connection with the shaft. While TriSpan procedures were mostly performed without medical antiaggregation, the pCONus should only be implanted under dual antiaggregation. Aneurysm asymmetry is of less concern. Due to the firm connection between the distal petals and the proximal shaft, the device shows a tendency to center itself in asymmetric aneurysms. Similar to the behavior of TriSpan, the ability of the pCONus to retain small coils inside an aneurysm is poor at the proximity of the neck. The coil occlusion of an aneurysm after pCONus deployment should be started with at least $13 \mathrm{D}$ coil, which might be intermingled with the petals and should be completed with long and soft coils with a diameter of no less than $3 \mathrm{~mm}$ - just as was done previously with 
the TriSpan. In the case of reperfusion of an aneurysm and endovascular retreatment, a previously detached TriSpan did not provide stability for further coils. In aneurysms treated with the pCONus, the petals of the first pCONus remain in the same position, again preventing coils from displacement.

The concept of intra-aneurysmal flow diversion has prompted the development of 2 similar devices: Woven EndoBridge (Sequent Medical, Aliso Viejo, California) and Luna (NFocus/Covidien). Both devices are spheric implants made from braided nitinol wires. They are introduced into the aneurysm fundus via a microcatheter. This concept will most likely play a role in the future treatment of WNBAs. There are, however, certain apparent issues. The device itself is more rigid than conventional stents or flow diverters, causing difficulty during the insertion. The sizing of these devices is critical, being less suitable for very large aneurysms and those with irregular shapes. Initial clinical results with Woven EndoBridge have been published, ${ }^{5-7}$ but still little is known about the mid- and long-term results with this device and aneurysm regrowth after Woven EndoBridge occlusion has been reported. ${ }^{37}$ In the case of recurrent or persistent perfusion of an aneurysm treated with these devices, retreatment can be difficult.

The aneurysm neck reconstruction device (PulseRider; Pulsar Vascular, San Jose, California) is a bifurcation stent that can be implanted in intracranial vessel bifurcations in front of wide-neck aneurysms to support coil occlusion. Turk et $\mathrm{al}^{38}$ reported a good performance in an animal model. Clinical data are not yet available, and safety and efficacy are currently not known.

\section{Limitations of This Series and the Device}

This series reports a single-center experience, which was evaluated in retrospect. The retrospective nature of the data analysis precluded an ethics committee approval. No external institution was involved in the collection and analysis of the data. The decision to use a pCONus was at the operator's discretion and not under a given study protocol. We tried to avoid both crossingstent placement and dual balloon remodeling, which is certainly an institutional preference and may be different at other centers. No effort was undertaken to compare the pCONus with other methods. A direct comparison of the pCONus and conventional single- or crossing-stent procedures is difficult to envision because both methods have different merits and drawbacks. Stent placement, for instance, has the advantage of permanently modifying the angulation of the vessel bifurcation, which may be advantageous. This particular aspect, however, cannot be expected from a pCONus treatment. The initial occlusion rate of pCONusassisted coiling in this small series with $60 \%$ complete occlusion or a neck remnant is explained by the challenging anatomy of the treated aneurysms. Early retreatment in 2 patients was a result of the unfulfilled expectation that spontaneous thrombosis of residual filling of the aneurysm would occur. Short-term follow-up results, however, were encouraging. Long-term follow-up data for aneurysms treated with the pCONus are missing. Neither the incidence of intimal hyperplasia in the proximal stent shaft nor the long-term stability of the aneurysm occlusion is known following treatment.

The pCONus device is certainly not suitable for all WNBAs. We expect limitations if the aneurysm fundus is smaller than 5 $\mathrm{mm}$ and if the relation of the depth/width is $>2$. For aneurysms with a neck diameter of $>15 \mathrm{~mm}$, the $15-\mathrm{mm}$ pCONus in its current design version may not provide sufficient coil retention. The additional use of a second pCONus or another stent may add safety under these rare circumstances. Recurrent perfusion of an aneurysm fundus after coiling may be an indication for microsurgical clipping. ${ }^{39}$ After pCONus implantation and if the position of the device is unchanged, the aneurysm neck will remain bridged by the struts of the pCONus, which will most likely interfere with the proper closure of an aneurysm clip.

\section{CONCLUSIONS}

Deployment of the pCONus inside selected WNBAs, both ruptured and unruptured, is well-controlled and safe. The device does not interfere with the subsequent catheterization of the aneurysms and allows coil occlusion of the aneurysm fundus with reliable protection of the efferent vessels. A temporary dual medical platelet-function inhibition is required. Coil compaction and aneurysm reperfusion are not prevented by the pCONus, but the device does also assist re-coiling. Clip ligation of recurrent aneurysms after pCONus implantation is discouraged.

\section{ACKNOWLEDGMENTS}

The authors are most grateful to James Lago for language revision of the manuscript.

Disclosures: Marta Aguilar-Pérez-RELATED: Consulting Fee or Honorarium: phenox, Comments: Animal experience with pCONus in rabbits, UNRELATED: Consultancy: phenox, Expert Testimony: phenox, ev3, ab Medica, Comments: compensated for service as proctor, Travel/Accommodations/Meeting Expenses Unrelated to Activities Listed: phenox, MicroVention. Wiebke Kurre-RELATED: Support for Travel to Meetings for the Study or Other Purposes: phenox, Comments: travel expenses for the meeting of the American Society of Neuroradiology, UNRELATED: Consultancy: phenox, Grants/Grants Pending: Covidien,* Comments: grant for stroke research; Payment for Lectures (including service on Speakers Bureaus): Covidien, Codman. Hansjörg Bäzner-UNRELATED: Payment for Lectures (including service on Speakers Bureaus): Biogen Idec, Bayer Vital, UCB Pharma, Boehringer Ingelheim. Hans Henkes—RELATED: Other: phenox, Comments: Cofounder, shareholder, UNRELATED: Board Membership: phenox, Payment for Lectures (including service on Speakers Bureaus): ev3/Covidien, phenox, Codman, ab Medica, Comments: modest compensation on a fee-for-service basis, Travel/Accommodations/ Meeting Expenses Unrelated to Activities Listed: phenox, MicroVention, ev3/Covidien, Other: ev3/Covidien, phenox, ab Medica, Comments: proctoring. Money paid to the institution.

\section{REFERENCES}

1. Spetzler RF, McDougall CG, Albuquerque FC, et al. The Barrow Ruptured Aneurysm Trial: 3-year results. J Neurosurg 2013;119:146-57

2. Pierot L, Spelle L, Vitry F; for the ATENA Investigators. Immediate clinical outcome of patients harboring unruptured intracranial aneurysms treated by endovascular approach: results of the ATENA study. Stroke 2008;39:2497-504

3. Brinjikji W, Cloft HJ, Kallmes DF. Difficult aneurysms for endovascular treatment: overwide or undertall? AJNR Am J Neuroradiol 2009;30:1513-17

4. Fischer S, Vadja Z, Aguilar Perez M, et al. Pipeline Embolization Device (PED) for neurovascular reconstruction: initial experience in the treatment of 101 aneurysms and dissections. Neuroradiology 2012;54:369-82

5. Pierot L, Liebig T, Sychra V, et al. Intrasaccular flow-disruption treatment of intracranial aneurysms: preliminary results of a multicenter clinical study. AJNR Am J Neuroradiol 2012;33:1232-38

6. Lubicz B, Mine B, Collignon L, et al. WEB device for endovascular 
treatment of wide-neck bifurcation aneurysms. AJNR Am J Neuroradiol 2013;34:1209-14

7. Pierot L, Klisch J, Cognard C, et al. Endovascular WEB flow disruption in middle cerebral artery aneurysms: preliminary feasibility, clinical, and anatomical results in a multicenter study. Neurosurgery 2013;73:27-34

8. Lubicz B, Bandeira A, Bruneau M, et al. Stenting is improving and stabilizing anatomical results of coiled intracranial aneurysms. Neuroradiology 2009;51:419-25

9. Moret J, Cognard C, Weill A, et al. The "remodelling technique" in the treatment of wide neck intracranial aneurysms: angiographic results and clinical follow-up in $\mathbf{5 6}$ cases. Interv Neuroradiol 1997;3:21-35

10. Raymond J, Guilbert F, Roy D. Neck-bridge device for endovascular treatment of wide-neck bifurcation aneurysms: initial experience. Radiology 2001;221:318-26

11. Horowitz M, Levy E, Sauvageau E, et al. Intra/extra-aneurysmal stent placement for management of complex and wide-neckedbifurcation aneurysms: eight cases using the waffle cone technique. Neurosurgery 2006;58(4 suppl 2):ONS-258-62, discussion ONS-262

12. Raymond J, Guilbert F, Weill A, et al. Long-term angiographic recurrences after selective endovascular treatment of aneurysms with detachable coils. Stroke 2003;34:1398-403

13. Cloft HJ, Joseph GJ, Tong FC, et al. Use of three-dimensional Guglielmi detachable coils in the treatment of wide-necked cerebral aneurysms. AJNR Am J Neuroradiol 2000;21:1312-14

14. Baxter BW, Rosso D, Lownie SP. Double microcatheter technique for detachable coil treatment of large, wide-necked intracranial aneurysms. AJNR Am J Neuroradiol 1998;19:1176-78

15. Arat A, Cil B. Double-balloon remodeling of wide-necked aneurysms distal to the circle of Willis. AJNR Am J Neuroradiol 2005; 26:1768-71

16. Spiotta AM, Bhalla T, Hussain MS, et al. An analysis of inflation times during balloon-assisted aneurysm coil embolization and ischemic complications. Stroke 2011;42:1051-55

17. Pierot L, Cognard C, Spelle L, et al. Safety and efficacy of balloon remodeling technique during endovascular treatment of intracranial aneurysms: critical review of the literature. AJNR Am J Neuroradiol 2012;33:12-15

18. Chalouhi N, Starke RM, Koltz MT, et al. Stent-assisted coiling versus balloon remodeling of wide-neck aneurysms: comparison of angiographic outcomes. AJNR Am J Neuroradiol 2013;34:1987-92

19. Krischek O, Miloslavski E, Fischer S, et al. A comparison of functional and physical properties of self-expanding intracranial stents [Neuroform3, Wingspan, Solitaire, Leo +, Enterprise]. Minim Invasive Neurosurg 2011;54:21-28

20. Adel JG, Sherma AK, Bendok BR. CT angiography for assessment of intracranial basilar apex aneurysm neck diameter reduction poststenting for treatment planning. Catheter Cardiovasc Interv 2010;75: $644-47$

21. Piotin M, Blanc R, Spelle L, et al. Stent-assisted coiling of intracranial aneurysms: clinical and angiographic results in 216 consecutive aneurysms. Stroke 2010;41:110-15

22. Gao B, Baharoglu MI, Cohen AD, et al. Stent-assisted coiling of intracranial bifurcation aneurysms leads to immediate and delayed intracranial vascular angle remodeling. AJNR Am J Neuroradiol 2012;33:649-54

23. Henkes $\mathrm{H}$, Kirsch M, Mariushi W, et al. Coil treatment of a fusiform upper basilar trunk aneurysm with a combination of "kissing" Neuroform stents, TriSpan-, 3D- and fibered coils, and permanent implantation of the microguidewires. Neuroradiology 2004;46: 464-68

24. Shapiro M, Becske T, Sahlein D, et al. Stent-supported aneurysm coiling: a literature survey of treatment and follow-up. AJNR Am J Neuroradiol 2012;33:159-63

25. Thorell WE, Chow MM, Woo HH, et al. Y-configured dual intracranial stent-assisted coil embolization for the treatment of widenecked basilar tip aneurysms. Neurosurgery 2005;56:1035-40

26. Lozen A, Manjila S, Rhiew R, et al. Y-stent-assisted coil embolization for the management of unruptured cerebral aneurysms: report of six cases. Acta Neurochir (Wien) 2009;151:1663-72

27. Cekirge HS, Yavuz K, Geyik S, et al. A novel "Y" stent flow diversion technique for the endovascular treatment of bifurcation aneurysms without endosaccular coiling. AJNR Am J Neuroradiol 2011;32: $1262-68$

28. Zhao KJ, Yang PF, Huang QH, et al. Y-configuration stent placement (crossing and kissing) for endovascular treatment of wideneck cerebral aneurysms located at $\mathbf{4}$ different bifurcation sites. AJNR Am J Neuroradiol 2012;33:1310-16

29. Fargen KM, Mocco J, Neal D, et al. A multicenter study of stentassisted coiling of cerebral aneurysms with a $\mathrm{Y}$ configuration. $\mathrm{Neu}$ rosurgery 2013;73:466-72

30. Park HR, Yoon SM, Shim JJ, et al. Waffle-cone technique using Solitaire AB stent. J Korean Neurosurg Soc 2012;51:222-26

31. Gruber TJ, Ogilvy CS, Hauck EF, et al. Endovascular treatment of a large aneurysm arising from a basilar trunk fenestration using the waffle-cone technique. Neurosurgery 2010;67(3 suppl operative): ONS140-44, discussion ONS144

32. Kelly ME, Turner RD 4th, Moskowitz SI, et al. Delayed migration of a self-expanding intracranial microstent. AJNR Am J Neuroradiol 2008;29:1959-60

33. Sychra V, Klisch J, Werner M, et al. Waffle-cone technique with SolitaireTM AB remodeling device: endovascular treatment of highly selected complex cerebral aneurysms. Neuroradiology 2011;53:961-72

34. Liu W, Kung DK, Policeni B, et al. Stent-assisted coil embolization of complex wide-necked bifurcation cerebral aneurysms using the "waffle cone" technique: a review of ten consecutive cases. Interv Neuroradiol 2012;18:20-28

35. Turk AS, Rappe AH, Villar F, et al. Evaluation of the TriSpan neck bridge device for the treatment of wide-necked aneurysms: an experimental study in canines. Stroke 2001;32:492-97

36. De Keukeleire K, Vanlangenhove P, Defreyne L. Evaluation of a neckbridge device to assist endovascular treatment of wide-neck aneurysms of the anterior circulation. AJNR Am J Neuroradiol 2008;29:73-78

37. Wallner AK, Broussalis E, Hauser T, et al. Coiling after treatment with the Woven EndoBridge cerebral aneurysm embolization device: a case report. Interv Neuroradiol 2012;18:208-12

38. Turk A, Turner RD, Tateshima S, et al. Novel aneurysm neck reconstruction device: initial experience in an experimental preclinical bifurcation aneurysm model. J Neurointerv Surg 2013;5:346-50

39. Nakamura M, Montibeller GR, Götz F, et al. Microsurgical clipping of previously coiled intracranial aneurysms. Clin Neurol Neurosurg 2013;115:1343-49 